\title{
Analysis of Transmission Losses of Power Grid Containing Wind Power Plant Power Dispatching and Control Center of State Grid Fuxin Electronic Power Supply Company
}

\author{
Zhao Xunan, Wang Xin, Zheng Wenze \\ Fuxin Power Supply Company of National Grid Liaoning Electric Power Co., Ltd \\ henxue1997@163.com
}

Keywords: Fuxin Power Grid; Wind Power; Line Loss; Transmission Loss of Power Grid

\begin{abstract}
Line loss consists of two parts: one is the unavoidable loss, such as the lost electric energy caused by resistance heating in the process of power transmission; the other is the avoidable loss, such as the excessive loss caused by the unreasonable power grid operation mode as well as the abstracting of electricity and electric leakage. The unreasonable power generation loss shall be minimized so as to effectively utilize the electric energy. This paper takes the Fuxin electronic power grid as an example to analyze the impact of centralized grid connection on the transmission loss of power grid and proposes the relevant measures and suggestions.
\end{abstract}

\section{Basic Information of Fuxin Wind Power Base}

Fuxin wind power plant is located in northwest of Fuxin region and the east of Zhangwu, where the wind power capacity that has been put into operation reaches $1.6933 \mathrm{KW}$. There are 6 transformer substations of $220 \mathrm{KV}$ and 5 transformer substations of $66 \mathrm{KV}$, which are sent to Jinzhou, Shenyang and other load centers through $220 \mathrm{KV}$ tie line. According to the urban planning of Fuxin, the installed capacity is expected to reach 16.167 million KW (increase by 12.55 million $\mathrm{KW}$ ) in 2015; among which, the thermal power will reach 8.117 million KW (increase by 6.3 million KW) and new energy reach 8.05 million KW (increase by 6.25 million $\mathrm{KW}$ ). The generating capacity will amount to 581 million kilowatt-hour.

\section{Transmission Losses Caused by Power Grid in Fuxin Region}

Considering the excellent wind resources in Fuxin region and the significant difference in line loss per unit of each wind power plant, the line loss is subject to installed capacity of wind power plant, grid-connected voltage level and power supply radius according to the computational formula of line loss. Most of the draught fan in Fuxin region can reach full capacity operation. Under high wind power rate, there is corresponding high line losses with scattered distribution of wind power plant, long outgoing circuit and high cost. During the process of expanded investment at the latter stage, the line loss will be further increased, testifying to the transmission loss number that cannot be ignored.

\section{Line Loss in Wind Power Plant with Large Installed Capacity}

Each parameter of electric transmission line in Zhangbei Wind Power Plant, Fubei Wind Power Plant and Zhangdong Wind Power Plant with large installed capacity is converted to $40 \mathrm{~cm}$ and Matlab adopted to generate the curve for wind power plant output/line loss

Despite the fact that the transmission loss of each wind power plant rises along with the increase in the output, they still vary from each other in terms of their amplification; for this reason, this paper offers an analysis of the line loss of transmission line.

The aforesaid wind power plants mainly adopt the wire of $2 *$ LGJ-400/35 and 2*LGJ-300/40. The curve above is then subject to derivation to obtain its first-order derivative, which is the line loss characteristics of the wires of two types (as shown in the following chart). 


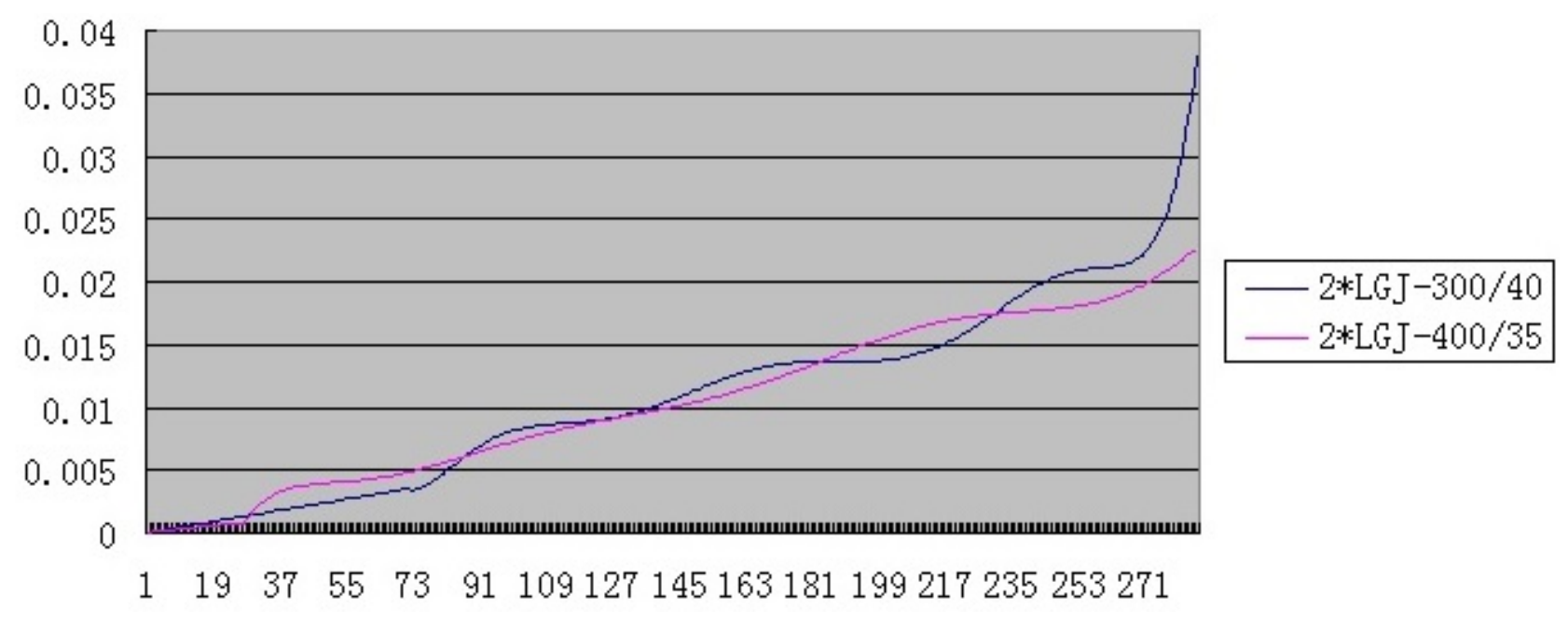

Fig. 1 Curve for the Rate of Change of Wire Line Loss

The following conclusions can be obtained from the chart above:

When the output of wind power plant is below 270 megawatt, the line loss rate of the wires with the type of $2 *$ LGJ-400/35 and $2 *$ LGJ-300/40 remain almost the same. In light of the cost of the construction of transmission line, it is suggested to choose the economical 2*LGJ-300/40 wire.

\section{Line Loss in Wind Power Plant with Small Installed Capacity}

Each parameter of the electric transmission line of wind power plant with small installed capacity, such as Fuxi Wind Power Plant, Fuxin Wind Power Plant, Zhalanshan Wind Power Plant, Gaoshanzi Wind Power Plant, Guben Wind Power Plant and Shijingao Wind Power Plant is converted to $30 \mathrm{~cm}$ and Matlab adopted to generate the curve for wind power plant output/line loss the curve is then subject to derivation to obtain its first-order derivative, which is the line loss characteristics of the wires of two types (as shown in the following chart).

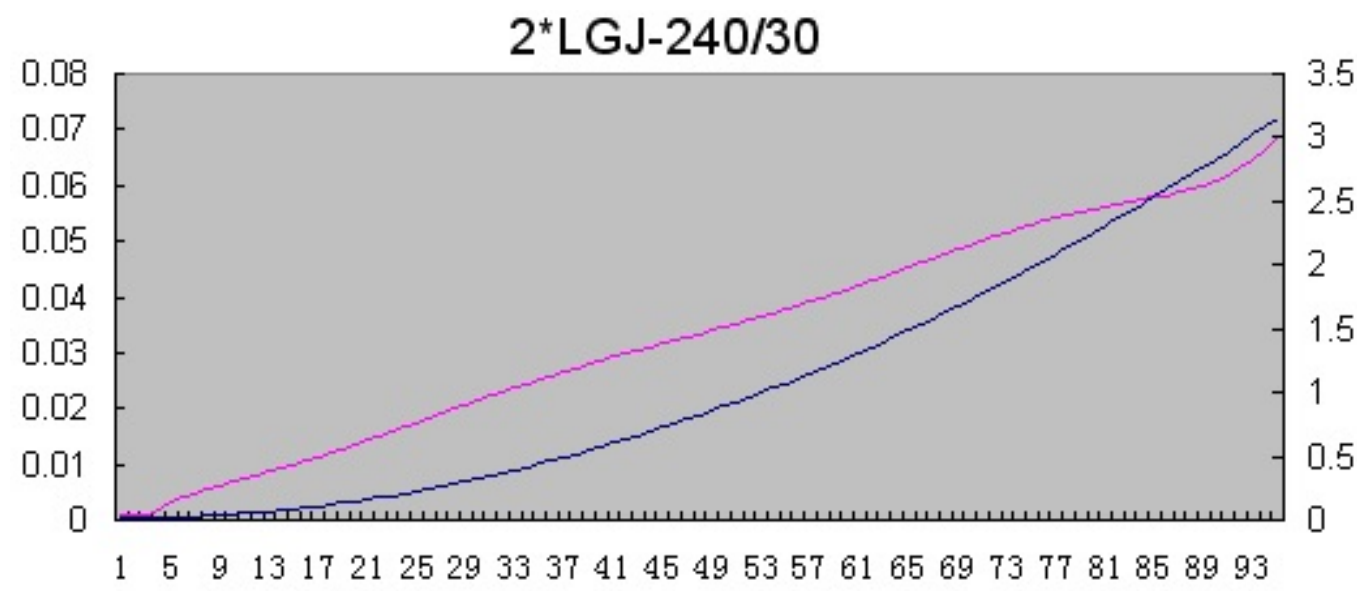

Fig. 2 Wire of $2 *$ LGJ-240/30

The following conclusions can be obtained from the chart above:

1) Under the same output, the line loss of $66 \mathrm{kV}$ wire is almost 10 times higher than that of $220 \mathrm{kV}$ wire.

2) The $2 *$ LGJ-240/30 wire is connected with the $66 \mathrm{kV}$ wind power plant. When the active output is below 90 megawatt, the line loss is more reasonable and economical.

3) In light of the economic line loss, the single circuit 2 divided conductor is obviously better than the double-circuit conductor.

In the wind power plant with the $66 \mathrm{kV}$ connected grid and the average active output of more than 90 megawatt, the economic current density should be taken into account with respect to the selection of the type. The economic current density refers to the corresponding current density at the 
lowest annual operation cost. Currently, the general economical current density of overhead line in China is shown in the following table.

Table 1 Economical Current Density

\begin{tabular}{|l|l|l|l|}
\hline Conductor Material & \multicolumn{4}{|l|}{ The Current Density per hour Used by the Maximal Load } \\
\hline & Below 3000h & $3000-5000 \mathrm{~h}$ & Above 5000h \\
\hline Aluminum & 1.65 & 1.15 & 0.9 \\
\hline Copper & 3.0 & 2.25 & 1.75 \\
\hline
\end{tabular}

With the economic current density and the maximal operating current, the economical section area can be calculated, namely, $\mathrm{Sj}=\mathrm{Ig} / \mathrm{Ij}$.

In the transmission line of wind power plant, the maximal load utilization time is dependent on the annual utilization hours of wind power plant. According to the discussion, the utilization hour is less than 3000 hours in Fuxin region besides the Shijingao Wind Power Plant; for this reason, the Ij is chosen as 1.65. The aforesaid formula is adopted to obtain the corresponding economical section area of power plant with different installed capacity.

Table 2 The Corresponding Economic Section Area of Wind Power Plant

\begin{tabular}{|c|c|c|c|}
\hline $\begin{array}{l}\text { Installed } \\
\text { Capacity/MW }\end{array}$ & Rated Current/A & $\begin{array}{l}\text { Economical Section } \\
\text { Area/mm2 }\end{array}$ & $\begin{array}{l}\text { Suggested } \\
\text { Area } \\
\text { Conductor/mm2 }\end{array}$ \\
\hline 90 & 791 & 479 & $2 * 240$ \\
\hline 114 & 990 & 600 & $2 * 300$ \\
\hline 152 & 1320 & 800 & $2 * 400$ \\
\hline
\end{tabular}

The calculation above can prove that when the active output of wind power plant is below 90 megawatt, it is reasonable to choose the wire with the type of $2 * \mathrm{LGJ}-240 / 30$.

Although the calculation has indicated that the line loss can be better controlled by the conductor with the type of $2 * \mathrm{LGJ}-300 / 40$ when the active output exceeds 114 megawatt. Owing to the erecting of conductor of $2 *$ LGJ-240/30 and $2 *$ LGJ-300/40, the tower, armour clamp and span length applied vary from each other, thus giving rise to the salient difference in the construction cost of transmission line. Therefore, it is demanding to offer analysis according to the installed capacity of wind power plant, distance of transmission line and the real-time cost price of steel and armour clamp.

\section{Influence of Power Supply Radius on Line Loss}

$$
R=r_{1} L \quad X=x_{1} L \quad\left\{\begin{array}{l}
\Delta P=\frac{P^{2}+Q^{2}}{U_{1}^{2}} R \times 10^{-3} \\
\Delta Q=\frac{P^{2}+Q^{2}}{U_{1}^{2}} X \times 10^{-3}
\end{array}\right.
$$

shows that the active and reactive loss on the line is in positive correlation with the length of the connected grid electronic lines; therefore, along with the increase in the length of connected grid electronic line, the loss is also on the rise.

For example, in the wind power plant with the installed capacity of 50 megawatt and $2 *$ LGJ240/30 line merged into $220 \mathrm{kV}$ voltage, the power factor of wind power plant is set as extra-0.98. With the active power of 50 megawatt under full operation capacity, the reactive power can reach 10.15 megawatt. Suppose the constant voltage of substation of $230 \mathrm{kV}$, the impedance and admittance of electric transmission line are converted into the function of line length. The following classical load flow calculation formula is adopted for the analysis of each parameter.

$$
\Delta P=\frac{P_{1}^{2}+Q_{1}^{2}}{U_{1}^{2}} R \times 10^{-3} \quad \Delta Q=\frac{P_{1}^{2}+Q_{1}^{2}}{U_{1}^{2}} X \times 10^{-3} \quad P_{2}=P_{1}-\Delta P \quad Q_{2}=Q_{1}-\Delta Q
$$

Under the wind power plant voltage of $230 \mathrm{kV}$, the active power and reactive power of transformer substation is calculated; then with the given constant voltage of $230 \mathrm{kV}$ and the active and reactive power calculated and by means of the following voltage drop formula, the busbar voltage of the wind power plant is calculated. 


$$
\Delta U=\frac{P_{1} R-Q_{1} X}{U_{1}} \quad U_{2}=U_{1}-\Delta U
$$

The aforesaid formula and iteration is applied for the solution, thus obtaining the more accurate power loss, voltage loss and the voltage of wind power plant. With the length of transmission line as the variable, it is possible to demonstrate the relationship with the busbar voltage of the wind power plant.

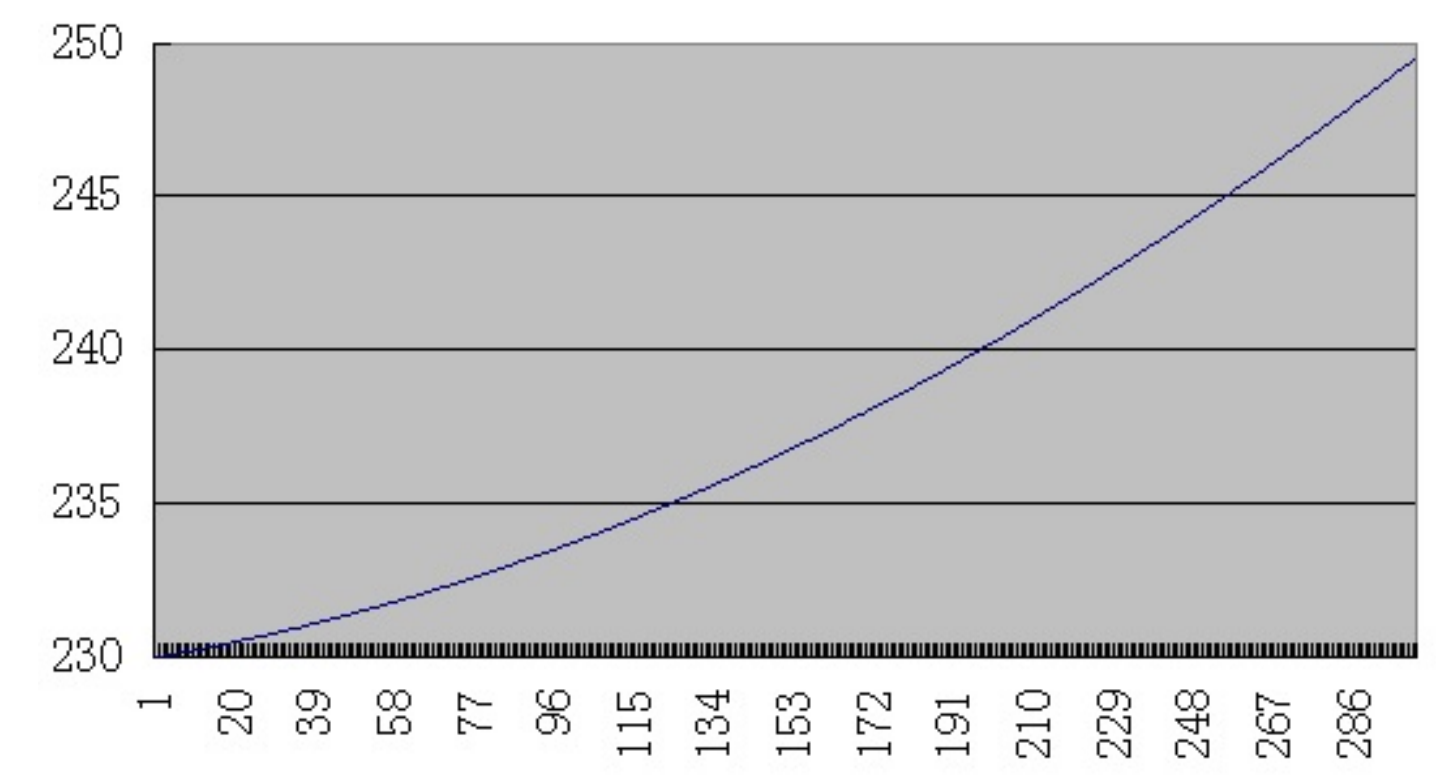

Fig. 3 The Busbar Voltage of 50 Megawatt Wind Power Plant along with the Change of Line Length

When the voltage of main station end is $230 \mathrm{kV}$ and remains unchanged, the terminal voltage will rise along with the increase in the length of transmission lines under the full capacity operation of wind power plant. With the length of 221 kilometers, the voltage of wind power plant will reach the upper limit value of $242 \mathrm{kV}$. In other words, when the wind power plant with the installed capacity of 50 megawatt is able to sustain the connected grid of $220 \mathrm{kV}$ voltage, the length of the connected grid line should not exceed 221 kilometers.

By means of the same analytic method, the voltage of wind power plant with different installed capacity along with the change of transmission line is calculated. Under the power factor of wind power plant of extra 0.98 , the active and reactive outputs of wind power plant with typical capacity under the full capacity operation is shown in the following table.

Table 3 The Corresponding Active and Reactive Outputs of Different Installed Capacity

\begin{tabular}{|l|l|l|l|}
\hline $\begin{array}{c}\text { Installed } \\
\text { Capacity } \\
\text { (Megawatt) }\end{array}$ & $\begin{array}{l}\text { Active Outputs } \\
\text { (Megawatt) }\end{array}$ & $\begin{array}{l}\text { Reactive Outputs } \\
\text { (Megawatt) }\end{array}$ & Power Factor \\
\hline 50 & 50 & 10.15 & 0.98 \\
\hline 100 & 100 & 20.30 & 0.98 \\
\hline 150 & 150 & 30.45 & 0.98 \\
\hline 200 & 200 & 40.61 & 0.98 \\
\hline 250 & 250 & 50.76 & 0.98 \\
\hline 300 & 300 & 60.91 & 0.98 \\
\hline 350 & 350 & 71.07 & 0.98 \\
\hline 400 & 400 & 81.22 & 0.98 \\
\hline 450 & 450 & 91.37 & 0.98 \\
\hline 500 & 500 & 101.52 & 0.98 \\
\hline
\end{tabular}

Each group of data is subject to calculation by means of iterative formula, thus obtaining the influence of line length on the voltage of wind power plant with the contrastive graph listed as below. 


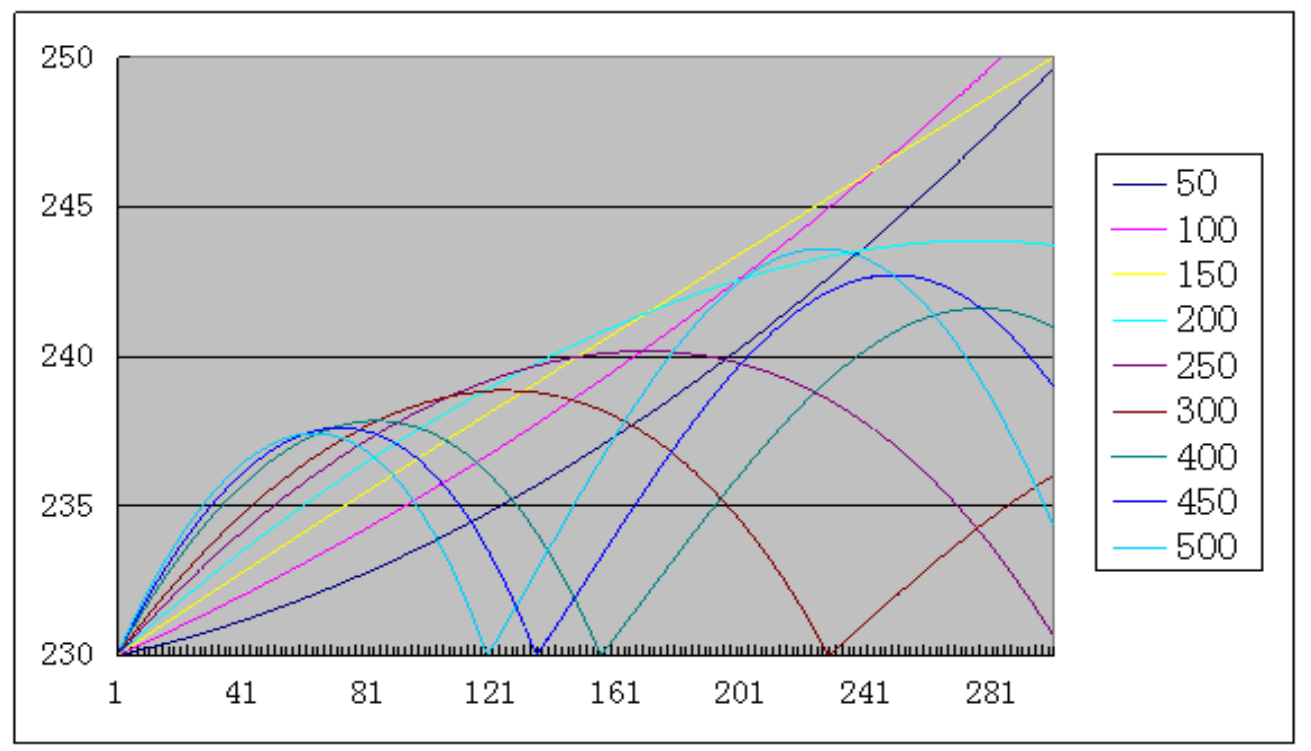

Fig. 4 The Corresponding of Busbar Voltage of the Line Length

As shown in the figure 4, under the full capacity operation with the capacity of over 200 megawatt, the terminal voltage gradually drops instead of rising along with the increase in line length. At particular moment, it is even lower than the terminal voltage. The calculation data and the actual operation of wind power plant reveal that along with the rise in line length and without the consideration of line impedance, its influence on electrical susceptance gradually appears and then becomes a decisive factor. It is suggested that the length of connected grid transmission line of 450 megawatt wind power plant shall not be made over 71 kilometers. There are also suitable transmission distance for the wind power plant with other installed capacity, which is shown as below.

Table 4 The Suggested Connected Grid Line Length for Different Installed Capacity

\begin{tabular}{|l|l|}
\hline Installed Capacity(Megawatt) & Suggested Transmission Distance (Kilometer) \\
\hline 50 & 220 \\
\hline 100 & 192 \\
\hline 150 & 178 \\
\hline 200 & 183 \\
\hline 250 & 169 \\
\hline 300 & 124 \\
\hline 350 & 97 \\
\hline 400 & 83 \\
\hline 450 & 72 \\
\hline 500 & 63 \\
\hline
\end{tabular}

The analysis of the impedance based on $2 *$ LGJ240/30 transmission line shows that despite the different suitable length obtained from line with different type, there is no need for respective calculation considering the positive correlation between impedance and line length and the no obvious difference between unit impedance of different types of lines.

\section{Conclusions}

The wind power has received worldwide attention for its low power cost and pollution-free characteristics. Many countries are vigorously developing their wind power with increase in their installed capacity year by year. Many deficiencies of wind power also pop up in the process of development of wind power. The randomness, fluctuation and intermittency of wind power have brought many issues to power gird, including the loss of the power grid in the area where wind power is integrated. As shown by the preceding text, by means of the data of the wind turbine generators and load flow calculation formula, the different installed capacity, the type of connected 
grid lines and the line loss are obtained to ensure the safe, steady, economical and quality operation of power grid.

\section{References}

[1] Li Xianqi. Research on the Stability of System Voltage of Variable Speed Wind turbine and Grid-connected Wind Power Plant [D]. Wuhan: Huazhong University of Science and Technology, 2008.

[2] Xu Yetong. Research on the Stability of Large-scale Wind Power Integration and Design of Regulation Scheme [D]. Beijing: North China Electric Power University, 2011.

[3] Li Hui, Wang Hesheng, Zhao Bin. Simulation Study on the Different Equivalent Model of Wind Power Plant [M]. Solar Power Journal, 2011,32 (7): 1005-1012.

[4] Guo Qinglai. On the closed-loop control of phased reactive power voltage in electricity system, Beijing: Tsinghua University, 2005.

[5] Yang Hua, Liang Haifeng, Li Gengyin. Voltage coordination and control measures of wind farms in doubly-fed induction generator, Automation of Power System, 2010, 35 (2): 112-126. 